Research Article

\title{
Experiment and Numerical Simulation of Wooden Door Frame
}

\author{
Eryu Zhu ${ }^{1},{ }^{1}$ Bin Wang, ${ }^{1}$ Dongqi Wei, ${ }^{2}$ and Li Zhu ${ }^{3}$ \\ ${ }^{1}$ School of Civil Engineering, Beijing Jiaotong University, Beijing 100044, China \\ ${ }^{2}$ CITIC Construction CO.,LTD., Beijing 100027, China \\ ${ }^{3}$ Metro Operation Technology Research and Development Center, Beijing Subway Operation Co.,Ltd., Beijing 102208, China
}

Correspondence should be addressed to Eryu Zhu; eyzhu@bjtu.edu.cn

Received 29 April 2021; Accepted 2 September 2021; Published 15 September 2021

Academic Editor: Antonio Gloria

Copyright (c) 2021 Eryu Zhu et al. This is an open access article distributed under the Creative Commons Attribution License, which permits unrestricted use, distribution, and reproduction in any medium, provided the original work is properly cited.

\begin{abstract}
To prevent the wooden door frame of traditional rural houses from being stuck due to diamond deformation under earthquake and improve the seismic capacity of rural houses, an innovative method of reinforcing the angular displacement of the wooden door frame with channel steel and the diagonal brace is proposed. The rationality of the finite element simulation is demonstrated by comparing the results of finite element simulation and quasistatic test based on reinforced and unreinforced wooden door frame specimens. On the basis of the finite element model of wooden door frame, the seismic performance of channel type and diagonal brace thickness of reinforced wooden door frame and the seismic performance of friction coefficient of unreinforced wooden door frame are studied, respectively. The results show that the lateral stiffness and the lateral bearing capacity of the reinforced wooden door frame increase with the increase of channel steel type and the diagonal brace thickness. The height of the channel steel section of the seismic reinforcement structure should be half of the unreinforced structure. With the increase of the friction coefficient, the lateral bearing capacity of the unreinforced wooden frame increases, while the ductility of the unreinforced wooden frame decreases.
\end{abstract}

\section{Introduction}

At present, the seismic research on residential houses is mostly concentrated in cities and towns, while the seismic research of traditional rural houses is relatively unpopular. In the past, the seismic reinforcement of houses was basically the reinforcement of maintenance structures, and the reinforcement method belongs to the overall stiffness reinforcement, which requires a lot of funds, while the proportion of funds invested in earthquake resistance and disaster reduction of rural houses in the country is small. With limited funds, the seismic reinforcement of traditional village buildings, especially the wooden door frame reinforcement, should be the top priority in seismic reinforcement in China.

At present, the research on mortise tenon joints, overall seismic performance, and reinforcement of traditional wooden structures in ancient buildings has been mature and systematic. The lateral load behavior of frame specimens of the Assam-type house under cyclic and monotonic loading was evaluated [1]. Through the research on the repair method of the flat steel and carbon fiber cloth of the tenon joints of the ancient residential houses in Huizhou, the calculation formula of the bearing capacity of the tenon joints of the ancient residential houses of Huizhou was summarized [2].

Nowadays, composite materials such as fiber-reinforced polymers (FRP) [3] and glass fiber-reinforced polymer (GFRP) come as a new option in order to improve structural capacity and stiffness of timber structures [4]. Based on the ancient timber structure that has been damaged by the earthquake, the seismic performance of the structure after repair with CFRP was studied [5]. The fiberglass pultruded rods were inserted from the bottom to the top of the timber beam, through areas of damage, to overcome the loss of shear properties [6]. Bonded fiber-reinforced polymer laminates are used for the strengthening and repair of wooden structural members [7]. Strengthening of wood members in shear using epoxy-bonded composite materials in the form of laminates or fabrics appears to be a highly 
effective technique [8], besides, the reinforcement of the old wood beams under bending loads through the use of CFRP materials [9]. The effectiveness of using CFRP sheets as reinforcement for bolted glulam beam-to-column connections was validated [10]. Xue et al. [11] presented the experimental study of a column-and-tie wooden structure and analyzed its seismic performance under seismic excitation. Sumida et al. [12] performed a shake table seismic performance assessment on a full-scale, two-story, Japanese conventional post and beam wood townhouse designed with the 2000 BSL. Kasal et al. [13] performed a series of dynamic experiments on two-story glue-laminated timber frames with fiber-reinforced joints to obtain connection characteristics. Okail et al. [14] presented the findings of shakingtable experiments conducted to examine the seismic performance of a full-scale, one-story, wood-framed structure with masonry veneer.

The full-scale timber frame walls were tested to study their performance under compression and the results indicated that the stud-to-stud connections offered better improvement of load carrying capacity for the specimens under compression [15]. Feio et al. [16] studied the strength capacity of a wood-wood mortise and tenon joint by physical testing of full-scale specimens. The performance of different semi- and nondestructive tests for assessing global joint strength was also evaluated. Experimental investigations were carried out [17] to provide input and benchmark data for developing a method to predict rounded dovetail connection strength. Leichti et al. [18] used joint-test data from the literature and computer models to assess the effect of various parameters on joint stiffness. Based on the quasistatic test of mortise and tenon joints with different embedded depths [19], the influence of wood wedge embedded depth on the initial stiffness of joints was studied. Based on the static loading test and low-cycle reciprocating loading test, the seismic performance of wooden frames in traditional Korean ancient buildings was studied [20]. The flexural and shear properties of the beams after reinforcement in the ancient buildings with wooden structures were studied [21-23]. Johns and Lacroix [24] carried out experimental research on the wood beams reinforced with carbon fiber and glass fiber. Triantafillou [25] analyzed the shear resistance of wood beams pasted with FRP sheets, gave the calculation formula of shear capacity, and carried out the experimental research of shear reinforcement with U-shaped FRP hoops. Pang et al. [26] studied the beam shoulder of Korean traditional ancient building wooden frame through static loading.

Although experts have conducted a lot of research on the performance of wood structures and their seismic reinforcement, most of which focus on a single component, node, or plane column frame, the research on the angular displacement reinforcement of the joints of the wooden door frame is basically rare. The wooden door frame of traditional wooden houses has the security problems of weak connection of tenon and mortise joints and insufficient lateral seismic capacity; the innovative seismic reinforcement method of wooden frame structure of the escape passage with channel steel and the diagonal brace is put forward, which changes the traditional overall stiffness reinforcement to the joint angular displacement reinforcement. The horizontal low-cycle reciprocating load test of two full-scale wooden door frame specimens is carried out. Based on the finite element model, the influence of parameters such as channel steel type, the thickness of the diagonal brace, and friction coefficient on the seismic performance of the wooden door frame is discussed.

\section{Experiment}

2.1. Specimen Preparation and Design. According to the field survey of traditional wooden door frame dwellings, the two wooden door frames are designed and manufactured according to the full scale. The components of the reinforced wooden door frame are shown in Figure 1.

2.1.1. Reinforced Wooden Door Frame. The reinforced wooden door frame is denoted as specimen A-2. The specimen is a composite structure with channel steel and the diagonal brace added at the joints of the wooden beam and column. The outer dimension of the specimen is $3000 \mathrm{~mm} \times 2750 \mathrm{~mm}$ and the thickness of the door frame is $60 \mathrm{~mm}$. The opening dimension of the middle and upper part is $2600 \mathrm{~mm} \times 2500 \mathrm{~mm}$, and the diameter of the wooden columns on both sides is $200 \mathrm{~mm}$, as shown in Figure 2.

The specific reinforcement measures are slotting on the front eave purlin and the front eave column, fastening the flange of the 10\# channel steel and the snap steel plate in the slot, and connecting with $10 \mathrm{~mm}$ diameter bolts. Weld joints are used in the snap steel plate and between the snap steel plate and the channel steel. Two pieces of diagonal brace surface steel plate and three pieces of diagonal brace linked steel plate form seismic diagonal brace, welded in the snap steel plate. Seismic reinforcement structure is formed by channel steel, snap steel plate, and seismic diagonal brace, as is shown in Figure 3. The reinforced wooden door frame specimen A-1 is shown in Figure 4.

Channel steel relates to timber beam and timber column by expansion bolts. The model of channel steel used to reinforce the wooden door frame is $5 \#$, and its model and specification are shown in Table 1.

Q235 steel is selected as the diagonal brace, with the yield strength of $235 \mathrm{Mpa}$, tensile strength of $370 \mathrm{Mpa}$, and elongation of $25.5 \%$. The thickness of the diagonal brace is $10 \mathrm{~mm}$. Dimension of the diagonal brace is shown in Figure 5.

2.1.2. Unreinforced Wooden Door Frame. The unreinforced wooden door frame is denoted as specimen A-1. The fabrication process of specimen A-1 is completely in accordance with the general practice of traditional wooden door frame dwellings and the components are connected by mortise and tenon joints. Except for the reinforcement device, other structural forms are the same as those of specimen A-1, as shown in Figure 6. 


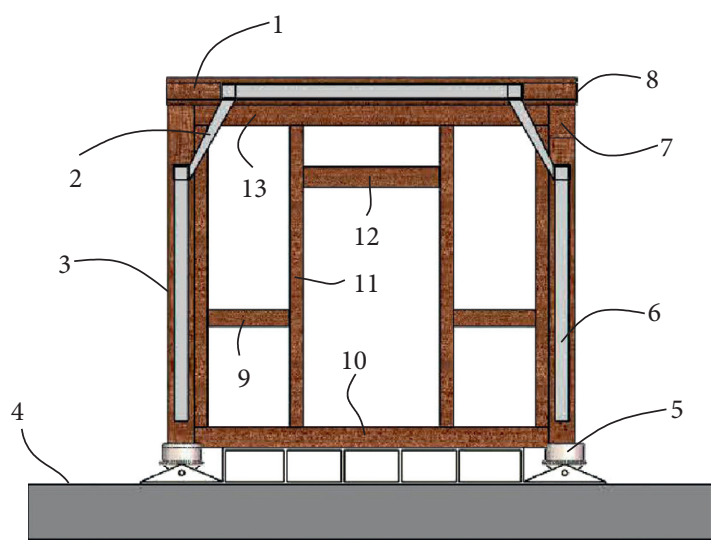

Figure 1: Component of the reinforced wooden door frame. Note: 1 refers to front eave purlin, 2 refers to diagonal brace, 3 refers to front eave column, 4 refers to bottom beam, 5 refers to hinged support, 6 refers to channel steel, 7 refers to pillars beam, 8 refers to the acting point of the actuator, 9 refers to waist wall, 10 refers to the lower sill, 11 refers to sky frame, 12 refers to the upper sill, and 13 refers to the upper holding frame.

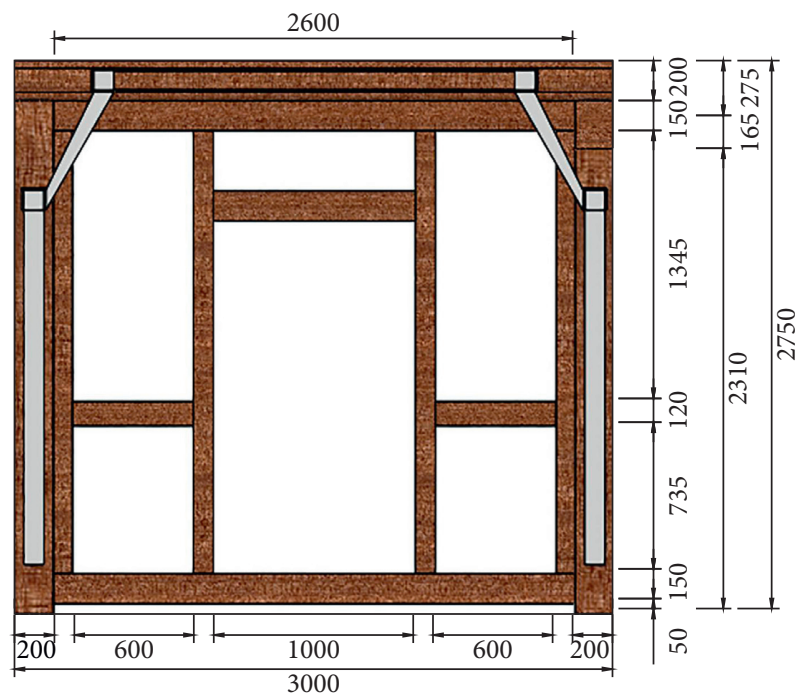

Figure 2: Size of specimen A-2.

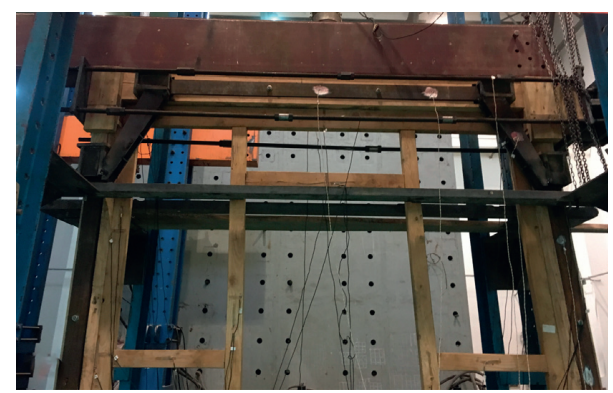

Figure 3: Channel steel and the diagonal brace.

2.2. Test Materials. The material used on the specimen is Pinus sylvestris var. mongolica. A batch of small test blocks is made and their mechanical properties are tested according to the national standard test method. The following mechanical properties of wood are tested: compressive strength,

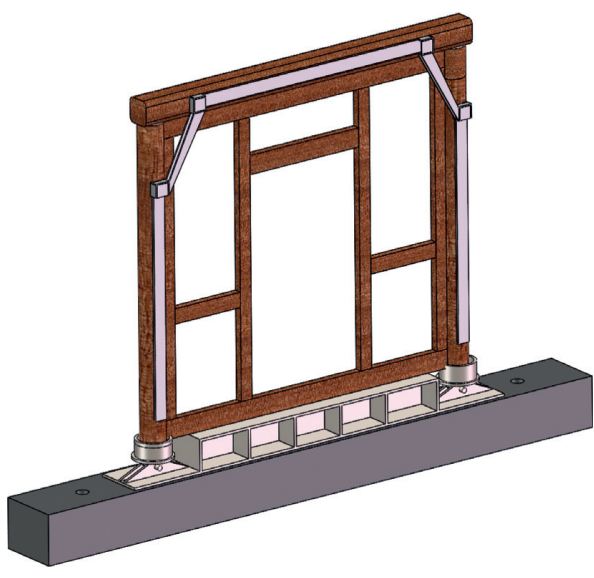

FIgURE 4: Specimen A-2.

tensile strength, shear strength along the grain, compressive elastic modulus, shear modulus, and Poisson's ratio air-dry density. See Figure 7 for the material properties test of the small test block strength index, and see Table 2 for the measured material parameters of wood.

\subsection{Test Equipment and Loading Measures}

2.3.1. Vertical Load and Horizontal Load. The vertical load of $46 \mathrm{kN}$ is applied to the wooden door frame through the vertical hydraulic Jack during the actual loading. The quasistatic test uses a displacement-controlled loading method. See Table 3 for the horizontal loading scheme of the two wooden door frame specimens.

In the quasistatic test, the wooden door frame specimen is very large. Therefore, a special test loading fixture is made, which consists of two small steel plates and two steel bars. The front eave purlin is clamped tightly with two small steel plates and two steel ties, and one of the steel ties is related to the horizontal actuator through bolts. The reinforcement tie is made of rebar with a diameter of $18 \mathrm{~cm}$. The horizontal and vertical loading devices are shown in Figure 8. The loading fixture is shown in Figure 9.

2.4. Layout Plan of Measuring Points. The strain gauge arrangement of the wooden door frame specimen is shown in Figure 10; the horizontal displacement of the top of the left column and the top of the right column should be measured, respectively, at the measuring point (1) and the measuring point (2). The displacement of the left tenon between the left waist sill and the left holding frame is measured at the measuring point (3) and the displacement of the right tenon between the right waist sill and the right holding frame at the measuring point (4). The vertical and horizontal displacement of the bottom of the column shall be measured at the measuring point (5), respectively, and the vertical and horizontal displacement of the bottom of the right column shall be measured at the measuring point (6), respectively. The strains at the left end of the beam are measured at the measuring point (7) and the strains at the right end of the beam are measured at the measuring point (8). 
TABle 1: Model and specification of channel steel.

\begin{tabular}{|c|c|c|c|c|}
\hline \multirow{2}{*}{ Channel steel model } & \multicolumn{3}{|c|}{ Section size $(\mathrm{mm})$} & \multirow{2}{*}{ Theoretical weight $(\mathrm{kg} / \mathrm{m})$} \\
\hline & Height $(h)$ & Leg width $(b)$ & Waist thickness $(d)$ & \\
\hline $5 \#$ & 50.00 & 37.00 & 4.50 & 5.44 \\
\hline
\end{tabular}

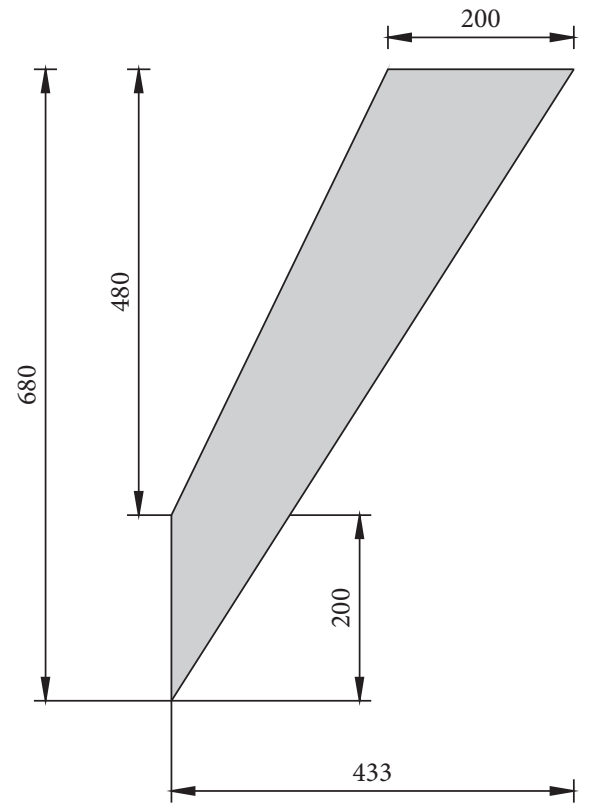

FIGURE 5: Dimension of the diagonal brace.

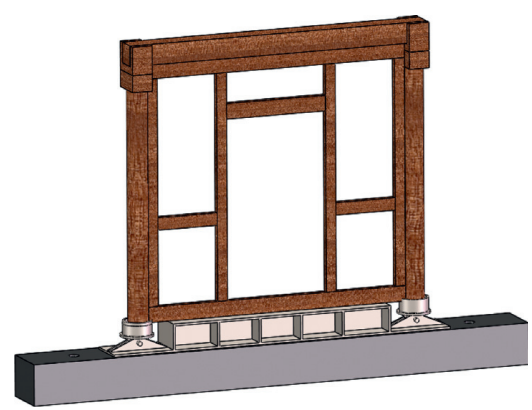

Figure 6: Specimen A-1.

\section{Finite Element Simulation Analysis}

3.1. Establishment of Finite Element Model for Wooden Door Frame. Abaqus finite element software is used to simulate the quasistatic test to verify the rationality of the quasistatic test and further analyze the wooden door frame. To be more consistent with the test, the constitutive model of wood is orthotropic elastic-plastic material. In Abaqus software, the wood constitutive law of elastic stage is determined by 9 engineering constants, including $E_{1}, E_{2}, E_{3}$, $v_{12}, v_{13}, v_{23}, G_{12}, G_{13}, G_{23}$. The wood components in the elastic stage showed the orthotropic property of wood, and the wood property data of Pinus sylvestris var. mongolica are used in the simulation. The Yamada-sun criterion is used in the plastic stage.

The interaction between mortise and tenon and the structure of the wooden door frame is simulated by face-to-

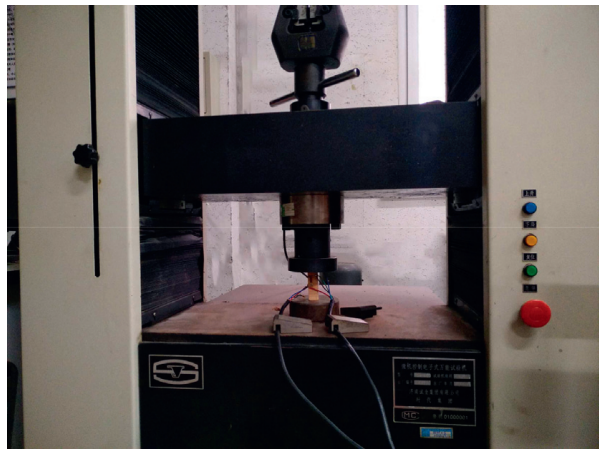

Figure 7: Material properties test of wood.

face contact. Tangential action between contact surfaces is in "hard contact" mode, and friction between contact surfaces is 0.3 .

The horizontal low-cycle reciprocating load is consistent with the loading in the quasistatic test, and the graded loading is used with $10 \mathrm{~mm}$ as the gradation. The maximum loading displacement of the unreinforced model is $200 \mathrm{~mm}$ and the loading time is $80 \mathrm{~s}$. The maximum loading displacement of the reinforced model is $160 \mathrm{~mm}$ and the loading time is $64 \mathrm{~s}$. The displacement loading curve is shown in Figure 11.

The schematic diagram of the models is shown in Figures 12 and 13.

\subsection{Comparison between Simulation and Test Results}

3.2.1. Skeleton Curve. As can be seen from Figure 14, the skeleton curves of specimen A-1 and the model wjg are basically consistent, and the changing trend is the same. As can be seen from Figure 15, the skeleton curves of specimen A-2 and model 10\#-20 basically match with the same trend of change. The error between the finite element results and the test results is due to the presence of initial defects in the wood used for the test.

As shown in Table 4, the key points on the skeleton curves of the specimen and the model are in good agreement. Except for the ductility coefficients $\mu_{\Delta}$ of model wjg and specimen A-1, the deviations of other seismic performance indexes are within $20 \%$, which can meet the actual needs of the project. The agreement of reinforced specimen A-2 with model 10\#-20 is higher than that of pure wood frame specimen A-1 with model wjg, because wood is a nonlinear material and the dispersion of the results is larger.

3.2.2. Stiffness Degradation Curve. As can be seen from Figure 16, the stiffness degradation curves of specimen A-1 and model wjg are basically consistent, and the changing trend is the same. As can be seen from Figure 17, the stiffness 
TABLE 2: Material parameters of wood (unit: $\mathrm{N} / \mathrm{mm}^{2}$ ).

\begin{tabular}{|c|c|c|c|c|c|c|}
\hline Compressive and tensile strength & $\begin{array}{c}f_{c, L} \\
26.50\end{array}$ & $\begin{array}{l}f_{c, R} \\
3.50\end{array}$ & $\begin{array}{l}f_{c, T} \\
2.80\end{array}$ & $\begin{array}{c}f_{t, L} \\
75.90\end{array}$ & $\begin{array}{c}f_{t, R} \\
2.80\end{array}$ & $\begin{array}{l}\tau_{L, R} \\
8.50\end{array}$ \\
\hline Modulus of elasticity and shear & $\begin{array}{c}E_{c, L} \\
11620.00\end{array}$ & $\begin{array}{c}E_{c, R} \\
1025.00\end{array}$ & $\begin{array}{c}E_{c, T} \\
587.00\end{array}$ & $\begin{array}{c}G_{L R} \\
1265.00\end{array}$ & $\begin{array}{c}G_{L T} \\
653.00\end{array}$ & $\begin{array}{c}G_{R T} \\
218.00\end{array}$ \\
\hline
\end{tabular}

Note. $f_{c, L}, f_{c, R}$, and $f_{c, T}$ are the longitudinal, radial, and tangential compressive strength of wood; $f_{t, L}, f_{t, R}$ are the longitudinal and radial tensile strength of wood; $\tau_{L, R}$ is the shear strength of wood along the grain diameter plane; $E_{c, L}, E_{c, R}$, and $E_{c, T}$ are the longitudinal, radial, and tangential compressive elastic modulus of wood; $G_{L R}, G_{L T}$, and $G_{R T}$ are the shear modulus of wood on the grain diameter plane, chord plane, and cross-section.

TABLE 3: Horizontal loading scheme.

\begin{tabular}{lcccc}
\hline Specimen number & Initial displacement $(\mathrm{mm})$ & Displacement gradation $(\mathrm{mm})$ & Cycle times & Maximum control displacement $(\mathrm{mm})$ \\
\hline A-1 & 0.00 & 10.00 & A circle & 200.00 \\
A-2 & 0.00 & 10.00 & A circle & 160.00 \\
\hline
\end{tabular}

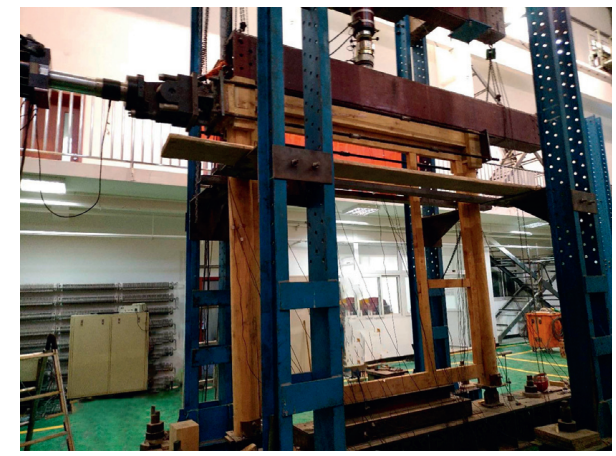

FIgURE 8: Vertical and horizontal loading devices.

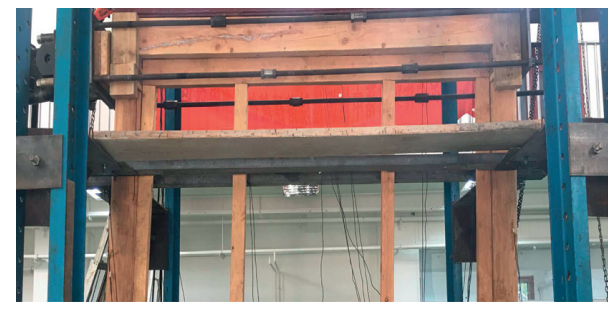

Figure 9: Loading fixture.

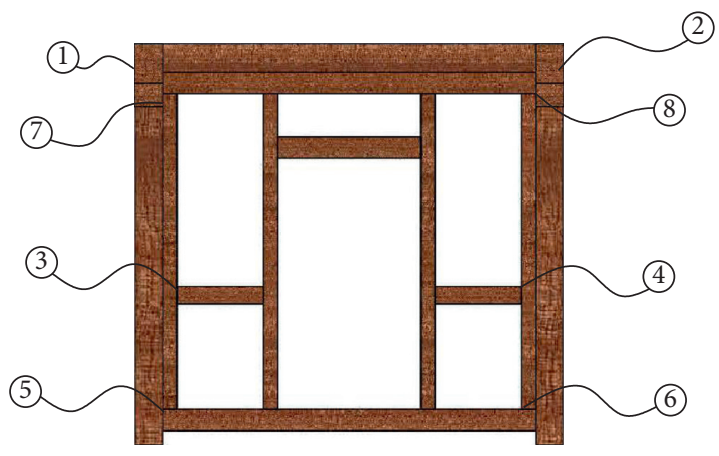

Figure 10: Arrangement of strain gauge.

degradation curves of specimen A-2 and model 10\#-20 basically match and the changing trend is the same. In summary, the finite element simulation results basically match with the test results, and the changing trend is consistent. The maximum relative errors between the

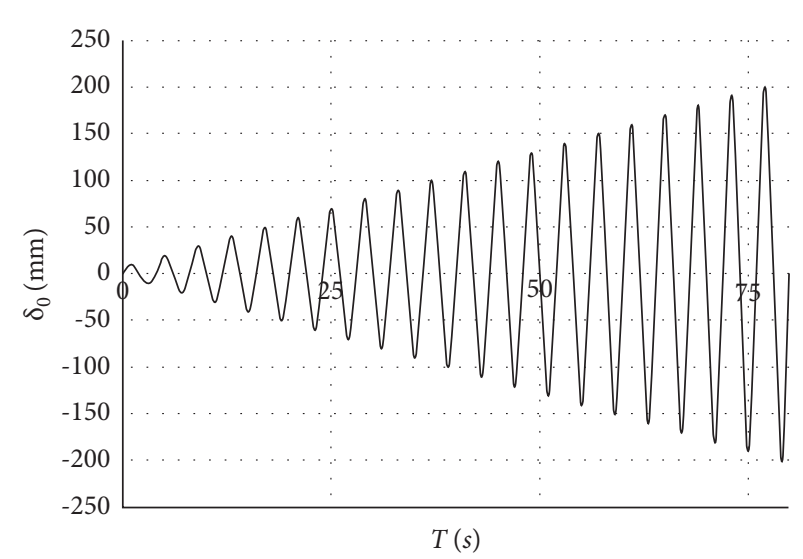

FIGURE 11: Displacement loading curve.

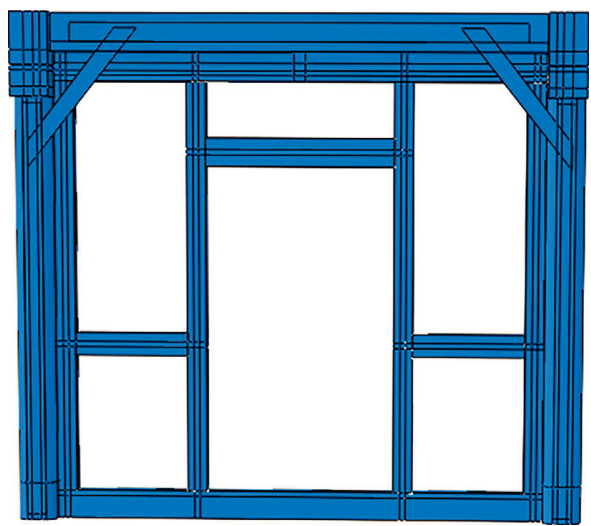

FIGURE 12: Reinforced wooden door frame 10\#-20.

experimental results and the FEM simulation results are basically within $20 \%$, which are within the acceptable range of engineering. Therefore, the finite element model can simulate the test reasonably, and the simulated results are reasonable and reliable.

\section{Parameter Analysis}

4.1. Influence of Channel Steel Type and the Diagonal Brace Thickness on Reinforcement Effect. 10\# channel steel and $20 \mathrm{~mm}$ thick diagonal brace are selected as the reinforcement 


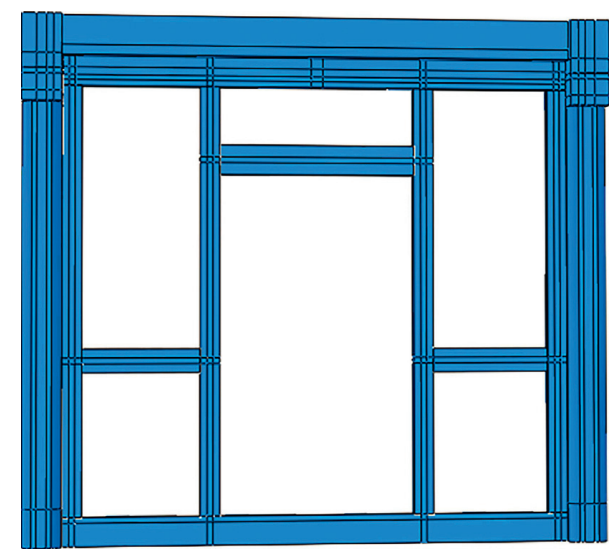

FIGURE 13: Unreinforced wooden door frame wjg.

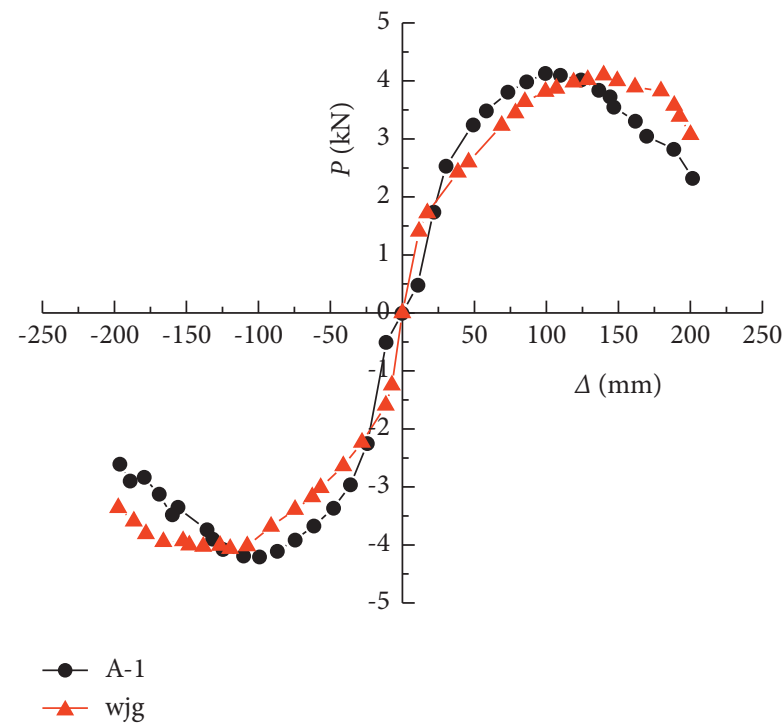

Figure 14: Skeleton curve of specimen A-1 and model wjg.

TABLE 4: Comparison of seismic performance indexes of specimen and model.

\begin{tabular}{lccccc}
\hline $\begin{array}{l}\text { Specimen } \\
\text { number }\end{array}$ & $\begin{array}{c}D_{y} \\
(\mathrm{~mm})\end{array}$ & $\begin{array}{c}D_{u} \\
(\mathrm{~mm})\end{array}$ & $\begin{array}{c}D_{\text {Fmax }} \\
(\mathrm{mm})\end{array}$ & $\begin{array}{c}F_{\max } \\
(\mathrm{kN})\end{array}$ & $\mu_{\Delta}$ \\
\hline wjg & 66.31 & 188.79 & 139.08 & 4.30 & 2.85 \\
A-1 & 77.53 & 170.56 & 120.00 & 4.21 & 2.20 \\
$10 \#-20$ & 124.39 & 160.00 & 160.00 & 36.90 & 1.29 \\
A-2 & 122.71 & 160.00 & 160.00 & 33.12 & 1.30 \\
\hline
\end{tabular}

scheme in the test. The thickness of the diagonal brace refers to the sum of the thicknesses of the two steel plates on the surface of the diagonal brace. This section studies the influence of channel steel type and the diagonal brace thickness on the reinforcement effect by changing channel steel type and the diagonal brace thickness. The model description of group B is shown in Table 5. See Table 6 for channel steel specifications of different types.

Based on the hysteretic curve, skeleton curve, and stiffness degradation curve, the seismic performance of 15 models is analyzed from the aspects of lateral bearing

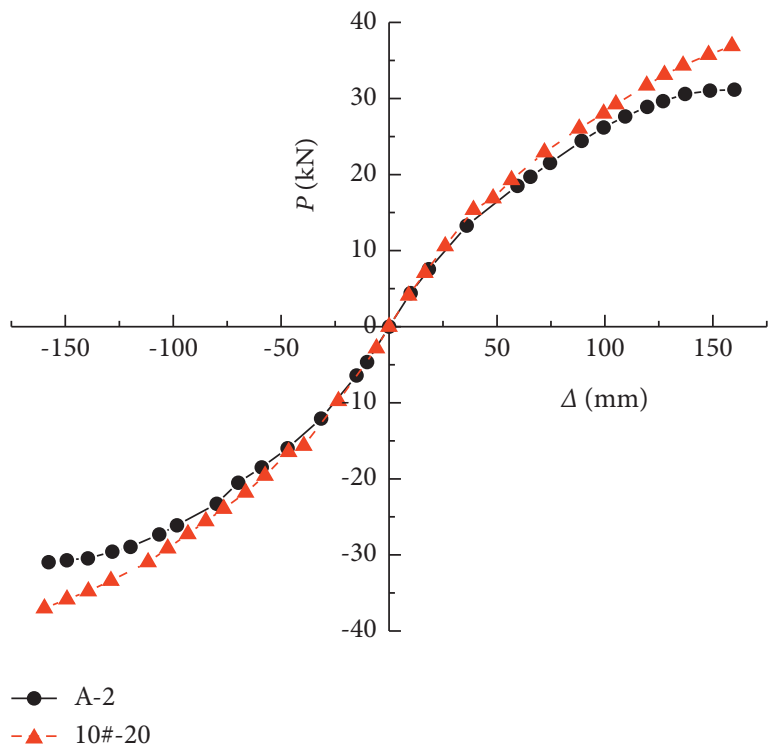

Figure 15: Skeleton curves of specimen A-2 and model 10\#-20.

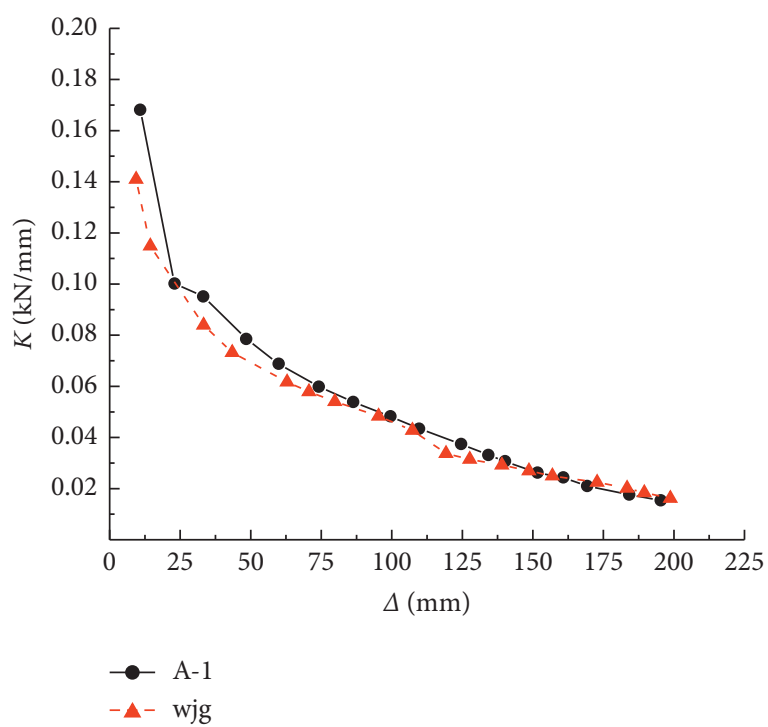

Figure 16: Stiffness degradation curves between specimen A-1 and model wjg.

capacity, ductility, stiffness degradation, and energy consumption.

From Figure 18, the skeleton curve of the reinforced wooden door frame is located above the unreinforced wooden door frame. With the increase of deformation, the difference of bearing capacity between the unreinforced wooden door frame and the reinforced wooden door frame is more obvious, which means that different reinforcement solutions have improved the ability of the wooden door frame to resist the load, and with the increase of deformation, the improvement of the ability of the wooden door frame to resist the load is more obvious.

As can be seen from Table 7, compared with the unreinforced wood door frame, the lateral bearing capacity of the reinforced wood door frame is significantly improved 


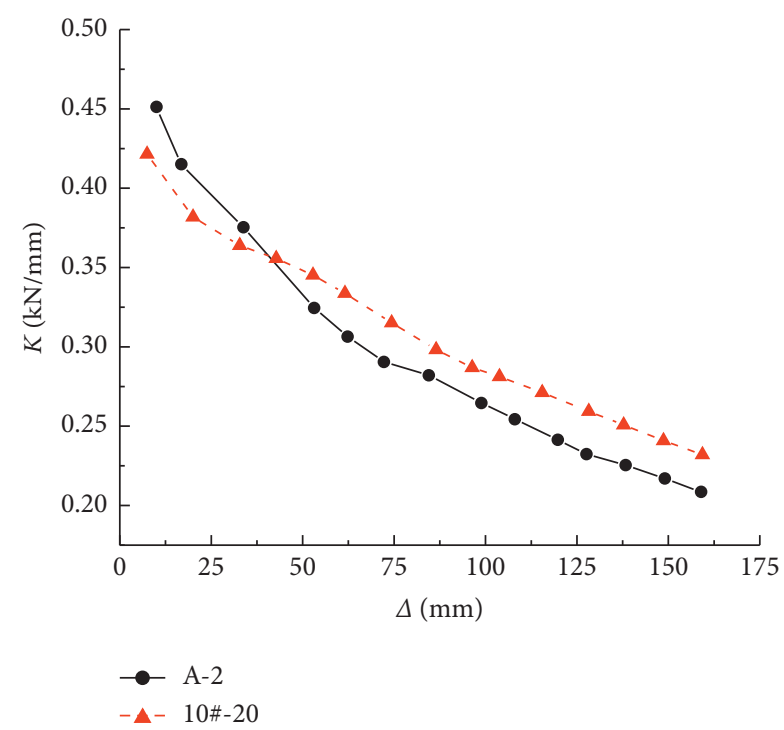

Figure 17: Stiffness degradation curves between specimen A-2 and model 10\#-20.

TABle 5: Group B models.

\begin{tabular}{lc}
\hline Model number & Model description \\
\hline wjg & Unreinforced \\
$5 \#-10$ & 5\# channel $+10 \mathrm{~mm}$ seismic diagonal brace \\
$5 \#-20$ & $5 \#$ channel $+20 \mathrm{~mm}$ seismic diagonal brace \\
$6.3 \#-10$ & 6.3\# channel $+10 \mathrm{~mm}$ seismic diagonal brace \\
$6.3 \#-20$ & 6.3\# channel $+20 \mathrm{~mm}$ seismic diagonal brace \\
$8 \#-10$ & 8\# channel $+10 \mathrm{~mm}$ seismic diagonal brace \\
$8 \#-20$ & 8\# channel $+20 \mathrm{~mm}$ seismic diagonal brace \\
$10 \#-10$ & $10 \#$ channel $+10 \mathrm{~mm}$ seismic diagonal brace \\
$10 \#-20$ & $10 \#$ channel $+10 \mathrm{~mm}$ seismic diagonal brace \\
$12.6 \#-10$ & $12.6 \#$ channel $+10 \mathrm{~mm}$ seismic diagonal brace \\
$12.6 \#-20$ & 12.6\# channel $+10 \mathrm{~mm}$ seismic diagonal brace \\
$14 \#$ a-10 & $14 \#$ a channel $+10 \mathrm{~mm}$ seismic diagonal brace \\
$14 \#$ a-20 & $14 \#$ a channel $+20 \mathrm{~mm}$ seismic diagonal brace \\
$16 \#$ a-10 & $16 \#$ a channel $+10 \mathrm{~mm}$ seismic diagonal brace \\
$16 \#$ a-20 & $16 \#$ a channel $+20 \mathrm{~mm}$ seismic diagonal brace \\
\hline
\end{tabular}

and the ductility coefficient is decreased. For the reinforced wood door frame, the lateral bearing capacity increases significantly with the increase of channel type, and the change of channel type has little effect on the ductility coefficient. Compared with the wooden door frame 5\#-20, the lateral bearing capacity of the wooden door frame 16\# a-20 is increased by $32.29 \%$.

With the increase of the thickness of the diagonal brace, the lateral bearing capacity increases significantly and the ductility coefficient decreases slightly. Compared with wood door frame 10\#-10, the lateral bearing capacity of the wooden door frame $10 \#-20$ is increased by $36.87 \%$ and the ductility coefficient is decreased by $3.7 \%$. Keeping the channel steel type of the wooden door frame unchanged, when the thickness of the diagonal brace of the wooden door frame is increased from $10 \mathrm{~mm}$ to $20 \mathrm{~mm}$, the lateral bearing capacity of the wooden door frame is increased by $20 \%-25 \%$ on average, indicating that the increase of diagonal brace thickness has a significant effect on the lateral bearing
TABLE 6: Specifications of channel steel of different types.

\begin{tabular}{lcccc}
\hline Channel & \multicolumn{3}{c}{ Section size $(\mathrm{mm})$} & \\
steel type & $\begin{array}{c}\text { Height } \\
(h)\end{array}$ & $\begin{array}{c}\text { Leg } \\
\text { width } \\
(b)\end{array}$ & $\begin{array}{c}\text { Waist } \\
\text { thickness }(d)\end{array}$ & $\begin{array}{c}\text { Theoretical } \\
\text { weight }(\mathrm{kg} / \mathrm{m})\end{array}$ \\
\hline $5 \#$ & 50.00 & 37.00 & 4.50 & 5.44 \\
$6.3 \#$ & 63.00 & 40.00 & 4.80 & 6.63 \\
$8 \#$ & 80.00 & 43.00 & 5.00 & 8.05 \\
$10 \#$ & 100.00 & 48.00 & 5.30 & 10.00 \\
$12.6 \#$ & 126.00 & 53.00 & 5.50 & 12.31 \\
$14 \#$ a & 140.00 & 58.00 & 6.00 & 14.53 \\
$16 \#$ a & 160.00 & 63.00 & 6.50 & 17.23 \\
\hline
\end{tabular}

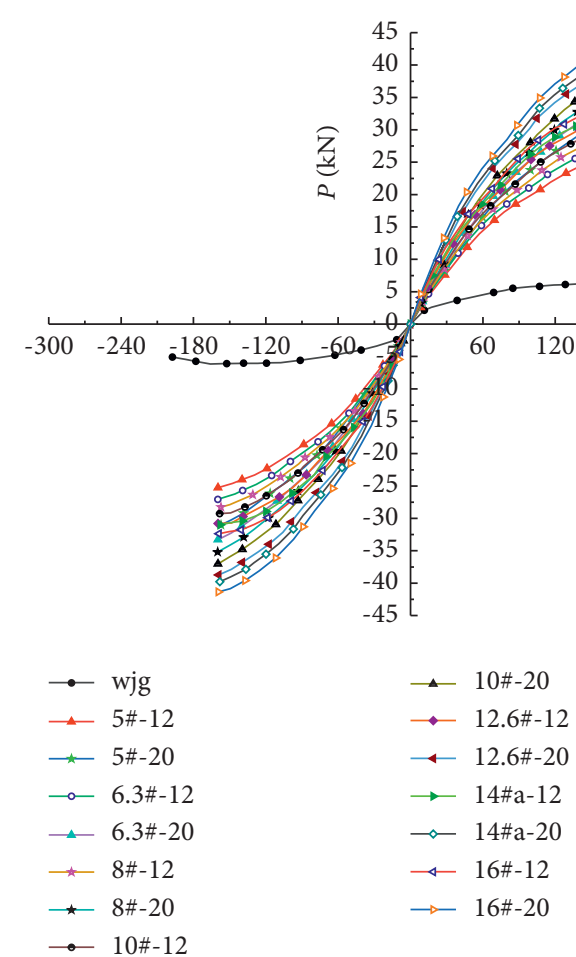

Figure 18: Skeleton curves of group B models.

capacity of the structure. Therefore, compared with the increase of channel steel type, the increase of diagonal brace stiffness is more obvious for the improvement of lateral bearing capacity of the structure.

It can be seen more intuitively from Figure 19 that the lateral bearing capacity of the reinforced wooden door frame is much larger than that of the unreinforced wooden door frame. The lateral bearing capacity of the reinforced wooden door frame increases with the increase of the channel steel type. The lateral bearing capacity of the reinforced wooden door frame increases with the increase of the thickness of the diagonal brace, and the increase of the thickness of the diagonal brace significantly improves the lateral bearing capacity of the wooden door frame. The lateral bearing capacity of the unreinforced wooden door frame is only $4.30 \mathrm{kN}$. The lateral bearing capacity of the reinforced wooden door frame is between $24 \mathrm{kN}$ and $41 \mathrm{kN}$. The lateral bearing capacity of the reinforced wooden door frame is significantly improved. 
TABLE 7: Seismic performance indexes of group B models.

\begin{tabular}{|c|c|c|c|c|c|}
\hline Model number & $D_{y}(\mathrm{~mm})$ & $D_{u}(\mathrm{~mm})$ & $D_{F \max }(\mathrm{mm})$ & $F_{\max }(\mathrm{kN})$ & $\mu_{\Delta}$ \\
\hline wjg & 66.31 & 188.79 & 139.08 & 4.30 & 2.85 \\
\hline $5 \#-10$ & 121.69 & 160.00 & 160.00 & 25.65 & 1.31 \\
\hline $5 \#-20$ & 128.62 & 160.00 & 160.00 & 31.43 & 1.24 \\
\hline $6.3 \#-10$ & 121.04 & 160.00 & 160.00 & 27.39 & 1.32 \\
\hline $6.3 \#-20$ & 126.54 & 160.00 & 160.00 & 33.20 & 1.26 \\
\hline $8 \#-10$ & 119.98 & 160.00 & 160.00 & 28.66 & 1.33 \\
\hline $8 \#-20$ & 125.51 & 160.00 & 160.00 & 35.08 & 1.27 \\
\hline $10 \#-10$ & 119.07 & 160.00 & 160.00 & 29.96 & 1.34 \\
\hline $10 \#-20$ & 124.39 & 160.00 & 160.00 & 36.90 & 1.29 \\
\hline $12.6 \#-10$ & 106.82 & 160.00 & 160.00 & 30.50 & 1.50 \\
\hline $12.6 \#-20$ & 121.14 & 160.00 & 160.00 & 39.15 & 1.32 \\
\hline $14 \# a-10$ & 109.49 & 160.00 & 160.00 & 31.47 & 1.46 \\
\hline $14 \# a-20$ & 118.59 & 160.00 & 160.00 & 40.23 & 1.35 \\
\hline $16 \# a-10$ & 97.25 & 160.00 & 160.00 & 32.87 & 1.65 \\
\hline $16 \# a-20$ & 115.88 & 160.00 & 160.00 & 41.58 & 1.38 \\
\hline
\end{tabular}

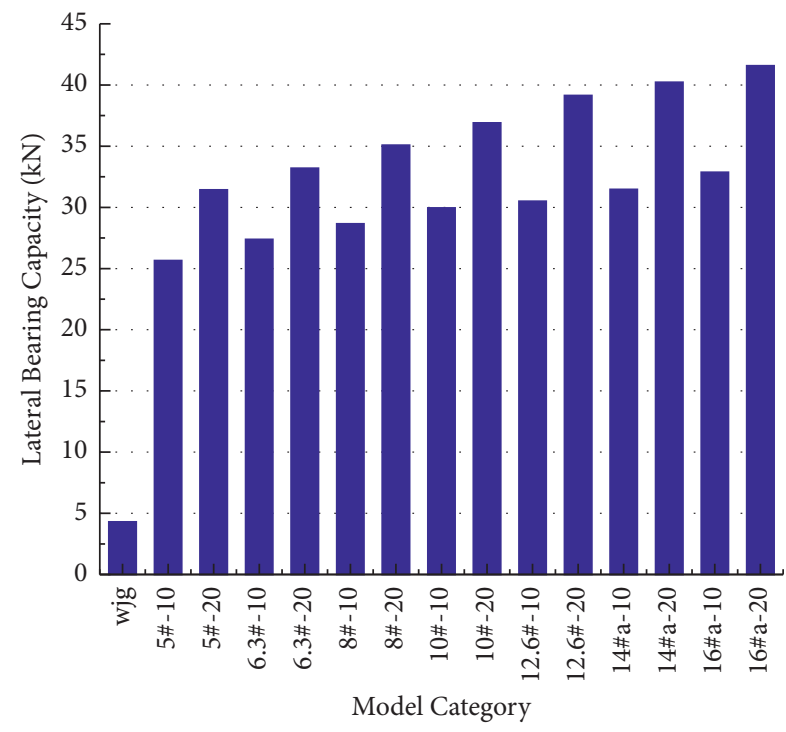

FIgURE 19: Ultimate bearing capacity of group B models.

It can be seen from Figure 20 that the stiffness degradation curve of the reinforced wooden door frame is always above the unreinforced wooden door frame during the whole loading process. The larger the channel steel type and the larger the thickness of the diagonal brace, the higher the position of the stiffness degradation curve. This shows the channel steel and the diagonal brace reinforcement significantly improve the lateral stiffness of the wooden door frame. For the reinforcement of wooden door frame, the larger the channel steel type, the larger the thickness of the diagonal brace, and the greater the lateral stiffness.

As shown in Figure 21, the displacement of the unreinforced wooden door frame is $139 \mathrm{~mm}$, while the displacement of the reinforced wooden door frame under the load of $4.30 \mathrm{kN}$ is only $12 \mathrm{~mm} \sim 28 \mathrm{~mm}$.

In summary, under the same loading displacement level, the load acting on the reinforced wooden door frame is much larger than that of the unreinforced wooden door frame. Compared with the unreinforced wooden door

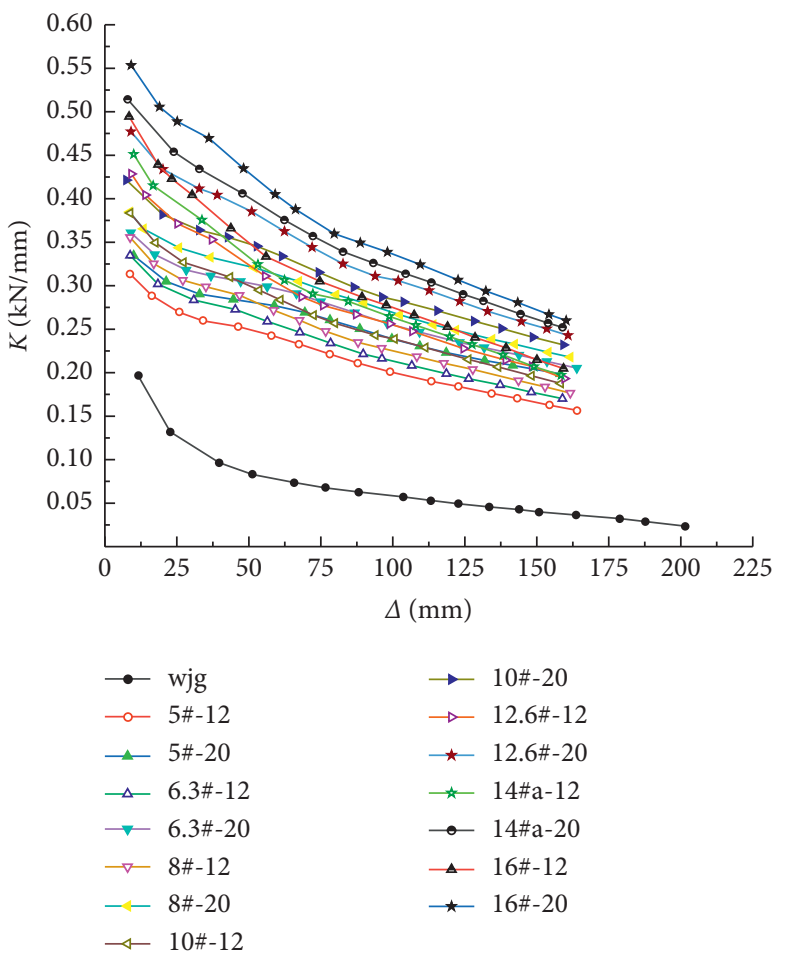

FIGURE 20: Stiffness degradation curves of group B models.

frame, the lateral bearing capacity of the reinforced wooden door frame is greatly improved. For the reinforcement of wooden door frame, the lateral stiffness and lateral bearing capacity of the structure increase significantly with the increase of channel steel type and the thickness of the diagonal brace.

Due to the material difference between steel and wood, the reinforcement effect of the wooden door frame reinforced with channel steel and the diagonal brace is very excellent, and the increase of the thickness of the diagonal brace significantly improves the bearing capacity of the wooden door frame. The increase of the channel steel type means the larger groove in the beam and column of the wooden door frame, which will 


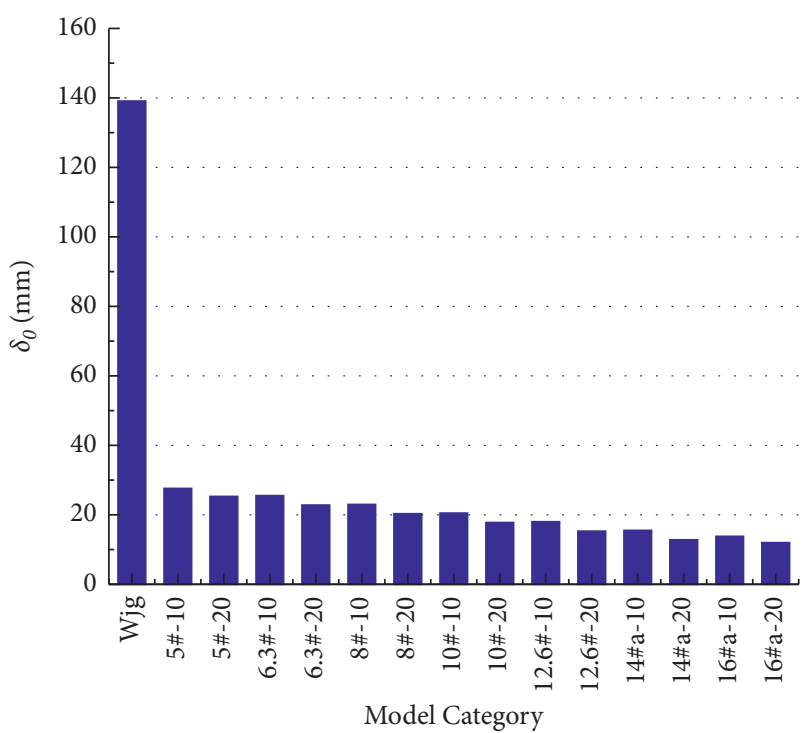

Figure 21: Displacement of group B models at $4.21 \mathrm{kN}$.

aggravate the cross-sectional damage to the wood. Therefore, it is recommended that the height of the channel steel section of the seismic reinforcement structure be half the height of the section of the unreinforced structure. For the wooden door frame in this paper, the recommended reinforcement scheme is $10 \#$ channel steel and $20 \mathrm{~mm}$ diagonal brace.

4.2. Influence of Friction Coefficient on the Seismic Performance of the Wooden Door Frame. For the wooden door frame, the greater the roughness between the contact surfaces of the members and between the contact surfaces of the mortise and tenon, the greater the static friction force to be overcome to produce relative sliding, which in turn affects the ability of the model to resist the load.

Keeping other parameters unchanged, only the friction coefficient of the model wjg is changed to study the effect of the friction coefficient on the seismic performance of the wooden door frame. The models are denoted as the group $\mathrm{C}$ models, as can been seen in Table 8 .

4.2.1. Hysteresis Curve. As shown in Figure 22, the hysteretic curves of group $\mathrm{C}$ models are all inverse Z-shaped, and the "pinching" effect near the origin is obvious, and the curve shapes are very similar.

4.2.2. Skeleton Curve. From Figure 23, the comparison of the skeleton curves of group $\mathrm{C}$ models with different friction coefficients can be seen. When $|\Delta| \leq 45 \mathrm{~mm}$, the overlap of the skeleton curves of group $\mathrm{C}$ models is relatively high. When $|\Delta| \geq 45 \mathrm{~mm}$, the load acting on the group $\mathrm{C}$ models increases with the increase of the model friction coefficient under the same displacement.

From Table 9, the lateral bearing capacity of the model increases with the increase of friction coefficient, because the greater the roughness between the contact surfaces of
TABLE 8: Group C models.

\begin{tabular}{lc}
\hline Model number & Friction coefficient \\
\hline wjg-mc 0.2 & $\mu=0.2$ \\
wjg-mc0.3 & $\mu=0.3$ \\
wjg-mc0.4 & $\mu=0.4$ \\
\hline
\end{tabular}

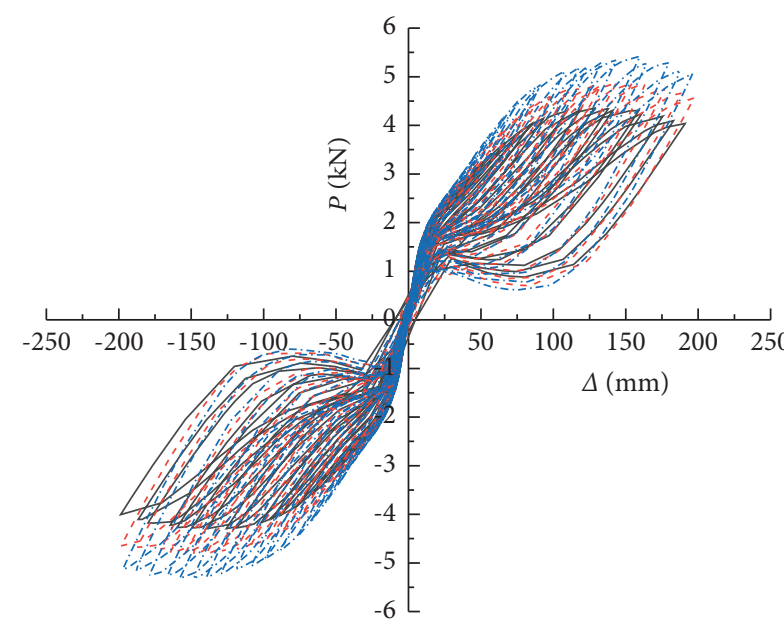

- wjg-mc0.2
--- wjg-mc0.3
.$--\quad$ wjg-mc0.4

Figure 22: Hysteretic curves of group C models.

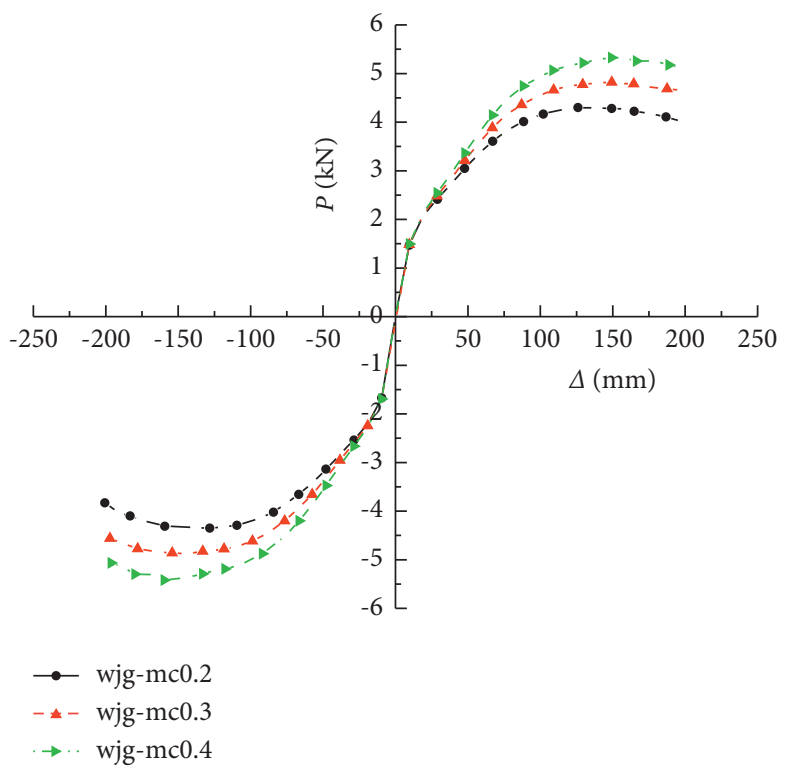

Figure 23: Skeleton curves of group C models.

the members and between the contact surfaces of the mortises and tenons, the greater the static friction force to be overcome to produce relative sliding, which further affects the bearing capacity of the model. The ductility coefficient of the model decreases with the increase of friction coefficient. 
TABLE 9: Seismic performance index of group C models.

\begin{tabular}{lccccc}
\hline $\begin{array}{l}\text { Specimen } \\
\text { number }\end{array}$ & $\begin{array}{c}D_{y} \\
(\mathrm{~mm})\end{array}$ & $\begin{array}{c}D_{u} \\
(\mathrm{~mm})\end{array}$ & $\begin{array}{c}D_{F \max } \\
(\mathrm{mm})\end{array}$ & $\begin{array}{c}F_{\max } \\
(\mathrm{kN})\end{array}$ & $\mu_{\Delta}$ \\
\hline wjg-mc0.2 & 56.85 & 192.46 & 131.05 & 3.78 & 3.39 \\
wjg-mc0.3 & 66.31 & 197.53 & 139.08 & 4.30 & 2.98 \\
wjg-mc0.4 & 74.34 & 200.00 & 145.31 & 4.82 & 2.69 \\
\hline
\end{tabular}

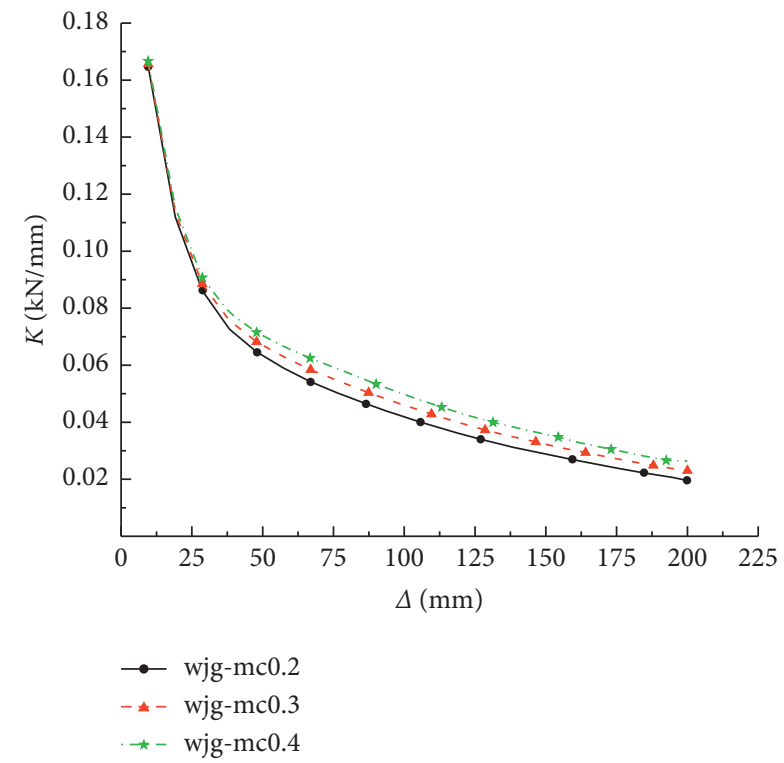

Figure 24: Stiffness degradation curves of group C models.

4.2.3. Stiffness Degradation Curve. As shown in Figure 24, when $\Delta \leq 45 \mathrm{~mm}$, the equivalent stiffness of group C models is very close; when $\Delta \geq 45 \mathrm{~mm}$, the stiffness difference between the group $\mathrm{C}$ models gradually expands, and the lateral stiffness of the model increases with the increase of the friction coefficient under the same displacement.

\section{Conclusions}

Based on the traditional wooden frame dwelling in Shuiyu Village, Fangshan District, Beijing, two wooden door frames are made according to $1 / 1$ full scale. The quasistatic tests of the two wooden door frames under horizontal low-cycle reciprocating load are completed. The rationality of the finite element simulation is demonstrated by comparing and analyzing the results of finite element simulation and experiments. On the basis, the influence of parameters such as channel steel type, the thickness of the diagonal brace, and friction coefficient on the seismic performance of the wooden door frame is studied through the finite element simulation. The main conclusions are as follows:

(1) The hysteresis curve of the unreinforced wooden door frame is inverse Z-shaped. The hysteresis curve of the reinforced wooden door frame is shuttleshaped fuller. The lateral bearing capacity and lateral stiffness of the reinforced wooden door frame are significantly increased, and the ductility is reduced to a certain extent.
(2) With the increase of channel steel type and the diagonal brace thickness, the lateral bearing capacity and lateral stiffness of the reinforced wooden door frame are improved. The increase of the thickness of diagonal braces very significantly improves the lateral bearing capacity of the reinforced wooden door frame. It is suggested that the height of the channel steel section of the seismic reinforced structure should be half of the height of the section of the unreinforced member structure to be strengthened. With the increase of friction coefficient, the lateral bearing capacity of the unreinforced wooden door frame increases, while the ductility of the unreinforced wooden door frame decreases.

The wooden door frame is an important escape route for residents under earthquake. It is of great social significance and scientific value to ensure the safety and stability of the escape route. In this paper, the seismic reinforcement method of using channel steel and diagonal braces to reinforce the wooden door frame of traditional residential houses is verified to be effective by experiments. By reinforcing the angular displacement of the wooden door frame, the diamond deformation of the traditional wooden door frame under earthquake is reduced, which can provide a reference for the transformation and reinforcement of traditional wooden door frames in rural areas in the future.

\section{Data Availability}

According to cooperation agreement, any type of data, including testing and recording, belongs to the unit and is therefore confidential to anyone else.

\section{Disclosure}

Eryu Zhu and Bin Wang should be regarded as co-first authors.

\section{Conflicts of Interest}

The authors declare that they have no conflicts of interest.

\section{Authors' Contributions}

Eryu Zhu and Bin Wang contributed equally to this work.

\section{Acknowledgments}

This research was supported by the National Natural Science Foundation of China (Grant no. 52172335).

\section{References}

[1] B. Chand, H. B. Kaushik, and S. Das, "Lateral load behavior of traditional Assam-type wooden house," Journal of Structural Engineering, vol. 145, no. 8, Article ID 04019072, 2019.

[2] Y. Li, W. Wang, and M. Wu, "Research on Mortise Nodes of Flat Steel, Carbon Fiber Reinforced Repair Method of Huizhou Ancient Residential Renovation," in Proceedings of 
the 2020 3rd International Conference of Green Buildings and Environmental Management, Qingdao, China, June 2020.

[3] J. Brol and A. Wdowiak-Postulak, "Old timber reinforcement with FRPs," Materials, vol. 12, no. 24, p. 13, 2019.

[4] D. Bru, F. J. Baeza, F. B. Varona, J. García-Barba, and S. Ivorra, "Static and dynamic properties of retrofitted timber beams using glass fiber reinforced polymers," Materials and Structures, vol. 49, no. 1-2, pp. 181-191, 2016.

[5] X. B. Zhao, F. L. Zhang, J. Y. Xue, and L. L. Ma, "Shaking table tests on seismic behavior of ancient timber structure reinforced with CFRP sheet," Engineering Structures, vol. 197, p. 16, 2019.

[6] D. W. Radford, D. Van Goethem, R. M. Gutkowski, and M. L. Peterson, "Composite repair of timber structures," Construction and Building Materials, vol. 16, no. 7, pp. 417425, 2002.

[7] K.-U. Schober, A. M. Harte, R. Kliger, R. Jockwer, Q. Xu, and J.-F. Chen, "FRP reinforcement of timber structures," Construction and Building Materials, vol. 97, pp. 106-118, 2015.

[8] T. C. Triantafillou, "Composites: a new possibility for the shear strengthening of concrete, masonry and wood," Composites Science and Technology, vol. 58, no. 8, pp. 1285-1295, 1998.

[9] A. Borri, M. Corradi, and A. Grazini, "A method for flexural reinforcement of old wood beams with CFRP materials," Composites Part B: Engineering, vol. 36, no. 2, pp. 143-153, 2005.

[10] X. Song, Y. Ma, X. Gu, and M. Wang, "Carbon fiber-reinforced polymer reinforcement for rotational behavior of bolted glulam beam-to-column connections," Journal of Composites for Construction, vol. 21, no. 3, Article ID 04016096, 2017.

[11] J. Xue, D. Xu, and L. Qi, "Experimental seismic response of a column-and-tie wooden structure," Advances in Structural Engineering, vol. 22, no. 8, pp. 1909-1922, 2019.

[12] K. Sumida, H. Isoda, T. Mori, K. Tanaka, and S. Tesfamariam, "Experimental seismic response of a Japanese conventional wooden house using 2016 kumamoto earthquake records," Journal of Performance of Constructed Facilities, vol. 33, no. 2, Article ID 04019014, 2019.

[13] B. Kasal, S. Pospisil, I. Jirovsky, A. Heiduschke, M. Drdacky, and P. Haller, "Seismic performance of laminated timber frames with fiber-reinforced joints," Earthquake Engineering \& Structural Dynamics, vol. 33, no. 5, pp. 633-646, 2004.

[14] H. O. Okail, P. B. Shing, W. M. McGinley, R. E. Klingner, S. Jo, and D. I. McLean, "Shaking-table tests of a full-scale singlestory masonry veneer wood-frame structure," Earthquake Engineering \& Structural Dynamics, vol. 40, no. 5, pp. 509530, 2011.

[15] F. Alinoori, P. Sharafi, F. Moshiri, and B. Samali, "Experimental investigation on load bearing capacity of full scaled light timber framed wall for mid-rise buildings," Construction and Building Materials, vol. 231, p. 11, 2020.

[16] A. O. Feio, P. B. Lourenço, and J. S. Machado, "Testing and modeling of a traditional timber mortise and tenon joint," Materials and Structures, vol. 47, no. 1, pp. 213-225, 2014.

[17] T. Tannert, F. Lam, and T. Vallée, "Strength prediction for rounded dovetail connections considering size effects," Journal of Engineering Mechanics, vol. 136, no. 3, pp. 358-366, 2010.

[18] R. J. Leichti, R. A. Hyde, M. L. French, and S. G. Camillos, "The continuum of connection rigidity in timber structures," Wood and Fiber Science, vol. 32, no. 1, pp. 11-19, 2000.
[19] S.-R. Han and J.-J. Lee, "Mechanical performance of Korean traditional wooden building of the column-girder tenon-joint by joint type," in Proceedings of the 9th World Conference on Timber Engineering, Portland, OR, USA, August 2006.

[20] J.-M. Seo, I.-K. Choi, and J.-R. Lee, "Static and cyclic behavior of wooden frames with tenon joints under lateral load," Journal of Structural Engineering, vol. 125, no. 3, pp. 344-349, 1999.

[21] H. Toutanji, L. Zhao, and Y. Zhang, "Flexural behavior of reinforced concrete beams externally strengthened with CFRP sheets bonded with an inorganic matrix," Engineering Structures, vol. 28, no. 4, pp. 557-566, 2006.

[22] C. Gentile, D. Svecova, and S. H. Rizkalla, "Timber beams strengthened with GFRP bars: development and applications," Journal of Composites for Construction, vol. 6, no. 1, pp. 11-20, 2002.

[23] M. Corradi, E. Speranzini, A. Borri, and A. Vignoli, "In-plane shear reinforcement of wood beam floors with FRP," Composites Part B: Engineering, vol. 37, no. 4-5, pp. 310-319, 2006.

[24] K. C. Johns and S. Lacroix, "Composite reinforcement of timber in bending," Canadian Journal of Civil Engineering, vol. 27, no. 5, pp. 899-906, 2000.

[25] T. C. Triantafillou, "Shear reinforcement of wood using FRP materials," Journal of Materials in Civil Engineering, vol. 9, no. 2, pp. 65-69, 1997.

[26] S.-J. Pang, J.-K. Oh, J.-S. Park, C.-Y. Park, and J.-J. Lee, "Moment-carrying capacity of dovetailed mortise and tenon joints with or without beam shoulder," Journal of Structural Engineering, vol. 137, no. 7, pp. 785-789, 2011. 